\title{
Application of Surface Geophysical Measurements to Groundwater Investigation
}

\author{
Alile O. M. ${ }^{1, *}$, Ujuanbi O. ${ }^{2}$, Iyoha A. ${ }^{2}$ \\ ${ }^{1}$ Physics Department, Covenant University, Ota, Nigeria \\ ${ }^{2}$ Department of Physics, Ambrose Alli University, Ekpoma
}

\begin{abstract}
In this research work, the schlumberger array was adopted. The investigation was carried out in two locations; Ambrose Alli University sports ground and Ujemen village area (Ekpoma environs) in the central part of Edo state, Nigeria. The interpretation of the data showed a resolution of six geoelectric layers. Analyzing the curves, the interpretation gave a total depth of $334.90 \mathrm{~m}(1115.22 \mathrm{ft})$ and $362.60 \mathrm{~m}(1207.46 \mathrm{ft})$ from both VES. Since the dropping of the resistivity in the VES curves indicates an aquifer layer, the depth zone corresponds to the existing saturated aquifer in the study area. These values are found to be in close correlation with the hydrogeological profile of the Ishan plateau. A maximum drill depth range of $320 \mathrm{~m}(1065.6 \mathrm{ft})$ to $350 \mathrm{~m}(1165.5 \mathrm{ft})$ in the study area is suggested.
\end{abstract}

Keywords Application, Surface Geophysics, Groundwater, Investigation

\section{Introduction}

Groundwater is characterized by a certain number of parameters which are determined by geophysical methods such as electrical resistivity methods, seismic methods, magnetic methods, gravity methods etc. But for this research work, the application of electrical resistivity survey method was used. The most usual parameters are the porosity, the permeability, the transmissivity and the conductivity. Electrical resistivity method in geophysical exploration for groundwater in a sedimentary environment has proven reliable (1). Records show that the depths of aquifers differ from place to place because of variational geo-thermal and geo-structural occurrence. $(2 ; 3)$.

The advent of technology has made the quest for water for all purpose in life to drift from ordinary search for surface water to prospecting for steady and reliable subsurface or ground water from boreholes. In Nigeria, presently, boreholes have rescued the citizenry from acute shortage of water.

Edo state has abundance of underground water as in several places in Nigeria. However, Edo Central have water are indications of variational aquifer characteristics resulting from disparity in lithological and structural formations, and sedimentation parameters. So, from Edo South to Edo Central the aquifer increases abruptly.

Ujemen and the Ambrose Alli University environs are highly populated areas of Edo Central in Edo State. As a

* Corresponding author:

owenalile@yahoo.co.uk (Alile O. M.)

Published online at http://journal.sapub.org/geo

Copyright (C) 2012 Scientific \& Academic Publishing. All Rights Reserved result, the quest for reliable potable water and in fact underground water is very high. Therefore the application of electrical resistivity method is important. This is so because electrical resistivity method is one of the most useful techniques in underground water geophysical exploration because the resistivity of rock is very sensitive to its water content. In turn, the resistivity of water is very sensitive to its ionic content.

The geology of the study area reveals that the entire area is underlain by sedimentary rocks. These rocks are of ages between Paleocene to recent. The sedimentary rock contains about 90 percent of sandstone and shale intercalation. It is coarse grained locally fine grained in some areas, poorly sorted, sub- angular to well rounded and bears lignite streaks and wood fragment (4).The sedimentary rock of the study area constitutes the Benin formation. This has an important groundwater reservoir. Large quantity of water is obtained in a place like Benin City.

This work is centered on geophysical investigation of underground water studies in a sedimentary environment by the application of vertical electrical sounding method using Schlumberger array configuration.

\section{Theory}

Ohms law provides the relationship between electric field and current density and it states that

$$
\bar{J}=\sigma \bar{E}
$$

$\sigma \Rightarrow$ conductivity (a constant)

For an isotropic medium, the conductivity will be a scalar quantity so that $\mathrm{J}$ and $\mathrm{E}$ will be in the same direction. For anisotropic medium, the conductivity is a tensor of second rank $\sigma_{i j}$ so that 


$$
\bar{J}=\sigma_{\mathrm{ij}} \bar{E}
$$

The subscript $i$ and $\mathrm{j}$ maybe any of the $\mathrm{X}, \mathrm{Y}$, or $\mathrm{Z}$ spatial directions. The basis of all resistivity prospecting with direct current is given by

$$
\nabla \sigma_{i j} \nabla V=0
$$

In the isotropic case equation 3 reduces to laplaces equation

$$
\nabla^{2} V=0
$$

For a horizontal earth model the solution to equation 4 according to Stefanesco et al (1930) becomes

$$
\mathrm{V}(\mathrm{r})=\frac{I \rho_{1}}{2 \pi}\left[\frac{1}{r}+2 \int_{0}^{\infty} \theta_{n}(\lambda) J_{0}(\lambda r) d r\right]
$$

Where $\mathrm{J}_{0} \bar{E}$ is the zero order Bessel function of the first kind and $\theta_{n}$, is called the kernel function which is a function of the thickness and reflection coefficient for an assumed earth model.

By differentiating equation (5), the Schlumberger apparent resistivity over an $\mathrm{n}$ - layered earth becomes

$$
\rho_{a}(r)=\rho_{1}\left[1+2 r^{2} \int_{0}^{\infty} \lambda \theta_{n}(\lambda) J_{1}(\lambda r) d \lambda\right]
$$

Where $\mathrm{J}_{1} \Rightarrow$ the first order Bessel function of the first kind.

The evaluation of this integral of equation (6) has been done in a number of ways. In this work we have adopted, Ghosh (1971) in which it is possible to determine a linear digital filter, which converts resistivity transform samples into apparent resistivity values for theoretical models.

\section{Materials and Methods}

In this research work, the schlumberger array in electrical resistivity survey was adopted. The basic field equipment for this study is the ABEM Terrameter SAS 3000 which displays apparent resistivity values digitally as computed from ohm's law. In this configuration, the four electrodes are positioned symmetrically along a straight line, the current electrodes on the outside and the potential electrodes on the inside. To change the depth range of the measurements, the current electrodes are displaced outwards while the potential electrodes in general, are left at the same position.

\section{HYDROGEOLOGICAL PROFILE OF ISHAN PLATEAU}

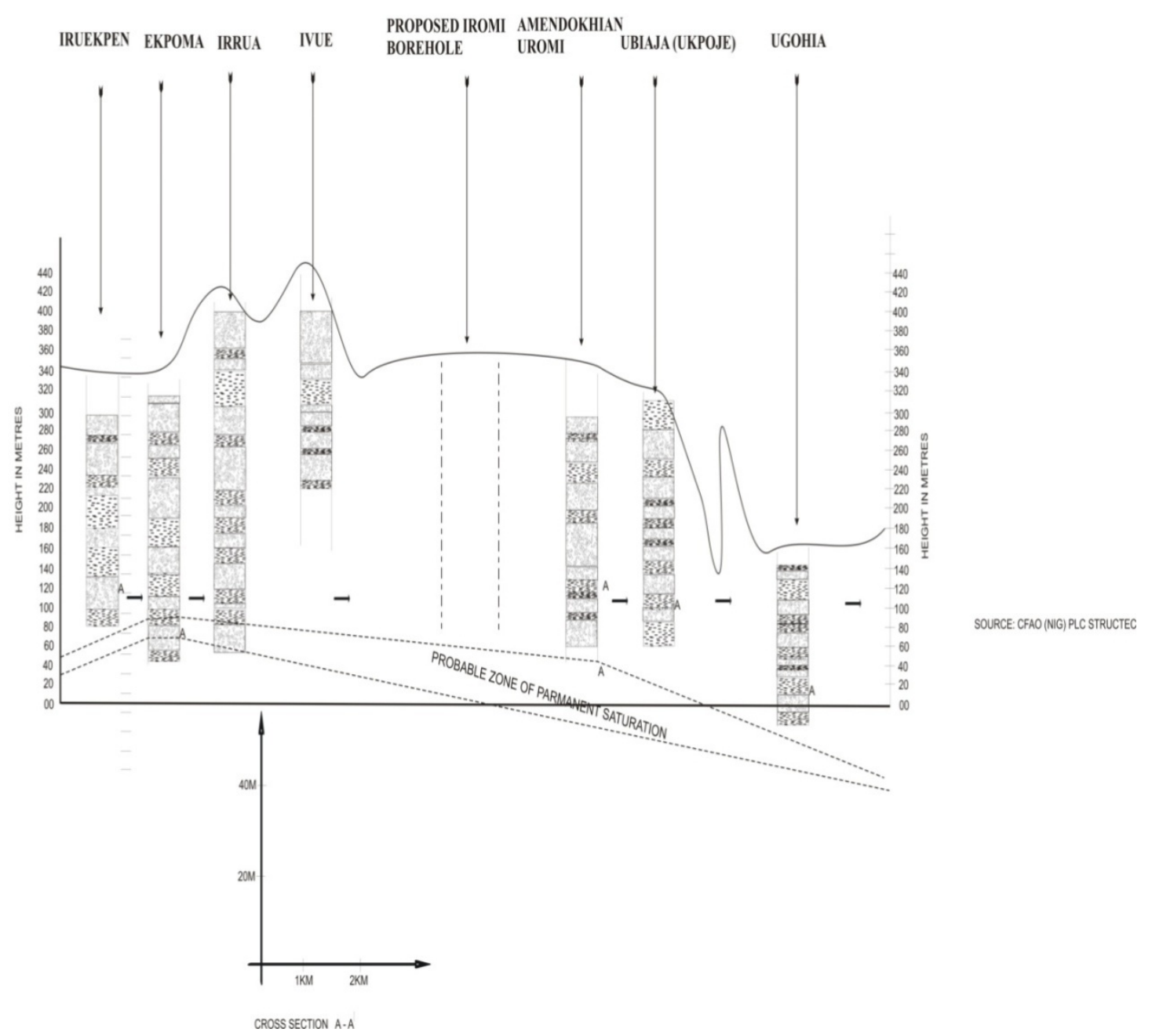

Figure 1. Hydrogeological Profile of Ishan Plateau (courtesy: CFAO Nig. Plc.) 
When the ratio of the distance between the current electrodes to that between the potential electrodes becomes too large, the potential electrodes must also be displaced outwards otherwise the potential difference becomes too small to be measured with sufficient accuracy (6).

Measurements of current and potential electrode positions are marked such that $\mathrm{AB} / 2 \geq \mathrm{MN} / 2$. Where $\mathrm{AB} / 2=$ Current electrode spacing and $\mathrm{MN} / 2=$ Potential electrode spacing.

Generally, the arrangement consists of a pair of current electrodes and a pair of potential electrodes. These are driven into the earth in a straight line to make a good contact with the earth. The current electrode spacing are expanded over a range of values for measurements in the field. The values of $\mathrm{AB} / 2$ increases as the measurements progresses while the potential electrodes separations are guided accordingly. The potential electrodes are kept at small separations relative to the current electrodes separations (7). One of the major advantages this method has over other methods is that only the current electrodes need to be shifted to new position for most readings while potential electrodes are kept constant for up to three or four readings (8). During the exploration work (field work) taking a sounding, the ABEM Terrameter SAS 300B (Self Averaging System) performs automatic recording of both voltage and current, stacks the results, computes the resistance in real time and digitally displays it. (9).

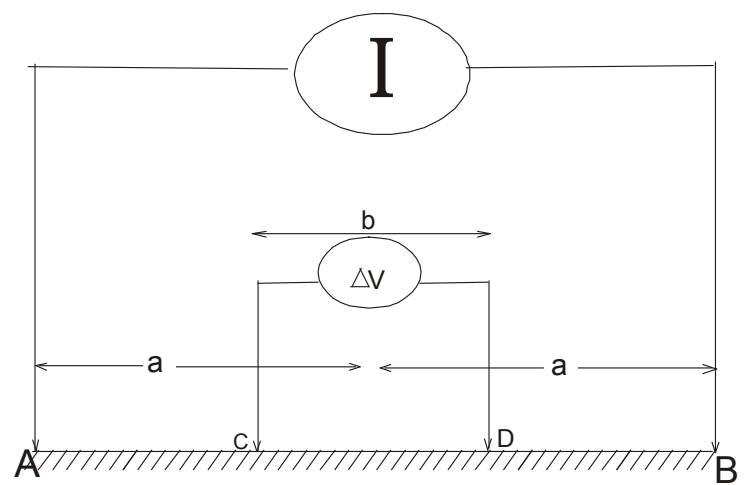

Figure 2. Schlumberger array

From the theory, we have that the potential at $\mathrm{C}$ due to $\mathrm{A}$ is

$$
\mathrm{V}_{\mathrm{c}}=\frac{\rho I}{2 \pi}\left\{\frac{1}{a-b / 2}-\frac{1}{a+b / 2}\right\}
$$

Where

$a \Rightarrow$ midpoint $\Rightarrow$ distance between the current electrodes and station.

$\mathrm{b} \Rightarrow$ distance between potential electrodes

$\rho \Rightarrow$ layer resistivity

The potential at $\mathrm{D}$ due to $\mathrm{A}$ becomes

$$
\mathrm{V}_{\mathrm{D}}=\frac{\rho I}{2 \pi}\left\{\frac{1}{a+b / 2}-\frac{1}{a-b / 2}\right\}
$$

The potential difference $\mathrm{dV}$ between the two potentials is therefore given by

$$
\begin{aligned}
& \mathrm{dV}=\mathrm{V}_{\mathrm{C}}-\mathrm{V}_{\mathrm{D}} \\
& \therefore \mathrm{dV}=\frac{\rho I}{2 \pi}\left\{\frac{1}{a-b / 2}-\frac{1}{a+b / 2}\right\}-
\end{aligned}
$$

$$
\begin{gathered}
\frac{\rho I}{2 \pi}\left\{\frac{1}{a+b / 2}-\frac{1}{a-b / 2}\right\} \\
\mathrm{dV}=\frac{\rho I}{2 \pi}\left\{\frac{2}{a-b / 2}-\frac{2}{a+b / 2}\right\} \\
\mathrm{dV}=\frac{\rho I}{2 \pi}\left(\frac{8 b}{4 a^{2}-b^{2}}\right)
\end{gathered}
$$

The apparent resistivity value is the product of the geometric factor and the resistance recorded in the resistivity meter. In each station, several soundings and apparent resistivity values will be obtained by expanding the current electrode spacing after each reading as required by Schlumberger array for deeper penetration into the earth and structural responses. The geometric factor, K, for Schlumberger configuration will be used. That is

$$
\begin{aligned}
K & =\frac{\pi}{2}\left\{\frac{(A B / 2)^{2}-(M N / 2)^{2}}{M N / 2}\right\} \\
\therefore K & =\pi C D\left\{\left(\frac{L}{C D}\right)^{2}-0.25\right\} \\
L & =2(A B / 2)
\end{aligned}
$$

\section{Results and Discussion}

The results of interpreted data for VES1 \& VES2 of the study area are respectively presented in plates $1 \& 2$. In VES1, the VES curve present a (KH) $\left(\rho_{1}<\rho_{2}>\rho_{3}<\rho_{4}\right)$ type-curve. The VES 2 (Ujemen), the VES curve presents a (KH) $\left(\rho_{1}<\right.$ $\left.\rho_{2}>\rho_{3}<\rho_{4}\right)$ type -curve. Both VES curves in Plate I and Plate II, showed an indication of aquifer layer since the curve shows a drop in the resistivity values. Computer interpretation of the VES curves resolves six (6) geoelectric layers for both VES. The geological interpretation of the resolved geoelectric layer is presented in figure 3 .

This is in correlation with the hydrogeological profile of Ishan plateau (fig.1). Analyzing the curves, the VES1 curve result gives a total depth of $334.90 \mathrm{~m}$ or $1115.22 \mathrm{Ft}$ and VES2 curve give a total depth of $362.60 \mathrm{~m}$ or $1207.46 \mathrm{ft}$. Correlating these with the hydrogeological profile of Ishan plateau of a total depth of $340 \mathrm{~m}$ (1122ft) for Ekpoma- Ujemen area. It is clear that both VES gives a very close correlation especially from the geologic picture presented in fig. 3 with the fig. 1 . Since the dropping of the resistivity in the VES curves indicates an aquifer layer, the depth zone corresponds to the existing saturated aquifer in the area. A maximum drill depth range of $320 \mathrm{~m}$ to $350 \mathrm{~m}$ can be advised.

\section{PLATE I}

Observed Ves: 1

L.G.A.: Esan West

Location: Aau Sports Complex

Weather: Hot

State: Edo 


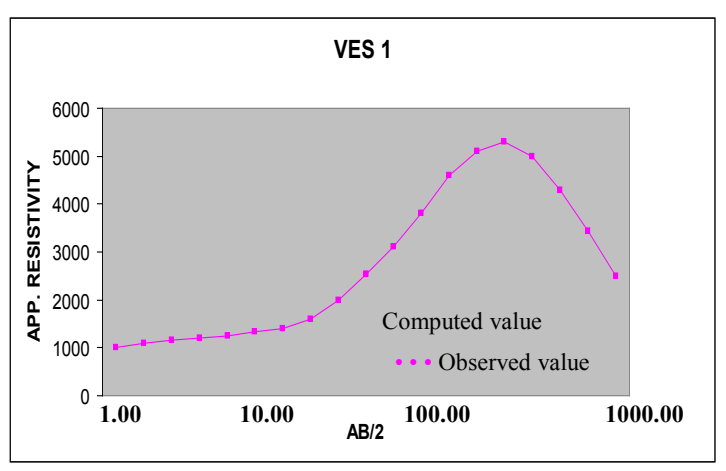

Observed (Field) and Computed (Theoretical) Data

\begin{tabular}{|c|c|c|}
\hline$\frac{A B}{2}(m)$ & $\begin{array}{c}\rho_{a}(o h m-m) \\
\text { OBSERVED VALUE }\end{array}$ & $\begin{array}{c}\rho_{a}(\text { ohm }-m) \\
\text { COMPUTED VALUE }\end{array}$ \\
\hline 1.00 & 1150.00 & 1109.62 \\
\hline 1.47 & 1085.92 & 1020.04 \\
\hline 2.15 & 1016.39 & 1016.06 \\
\hline 3.16 & 1078.77 & 890.00 \\
\hline 4.64 & 1245.47 & 890.00 \\
\hline 6.81 & 1341.87 & 950.00 \\
\hline 10.00 & 1501.04 & 1100.00 \\
\hline 14.70 & 1485.00 & 1400.00 \\
\hline 21.50 & 1582.05 & 1890.00 \\
\hline 31.60 & 3136.28 & 2500.00 \\
\hline 46.40 & 3152.12 & 3000.00 \\
\hline 68.10 & 3787.25 & 3666.27 \\
\hline 100.00 & 471.19 & 4600.00 \\
\hline 147.00 & 6247.42 & 5160.00 \\
\hline 215.00 & 7260.49 & 5800.00 \\
\hline 250.00 & 5678.89 & 6370.00 \\
\hline 300.00 & 4567.90 & 6680.00 \\
\hline 400.00 & 3447.89 & 6950.00 \\
\hline 500.00 & 3400.67 & 7110.00 \\
\hline 600.00 & 3045.87 & 6740.00 \\
\hline 700.00 & 2789.56 & 5840.00 \\
\hline 800.00 & 2568.32 & 4680.00 \\
\hline
\end{tabular}

Model Parameters

\begin{tabular}{|c|c|c|c|}
\hline $\begin{array}{c}\text { Geoelectric } \\
\text { Layer }\end{array}$ & $\begin{array}{c}\text { Resistivity } \\
(\text { ohm-m) }\end{array}$ & Thickness(m) & $\begin{array}{c}\text { Cumulative } \\
\text { Thickness(m) }\end{array}$ \\
\hline 1 & 1602.00 & 3.10 & 3.10 \\
\hline 2 & 3129.00 & 13.10 & 16.20 \\
\hline 3 & 4954.00 & 53.30 & 69.50 \\
\hline 4 & 25471.00 & 100.70 & 170.20 \\
\hline 5 & 1159.00 & 164.70 & 334.90 \\
\hline 6 & 37466.00 & infinity & Infinity \\
\hline
\end{tabular}

RMS Error (\%): 1.57

\section{PLATE II}

Observed Ves: 2

L.G.A.: Esan West

Location: Ujemen

Weather: Cool

State: Edo

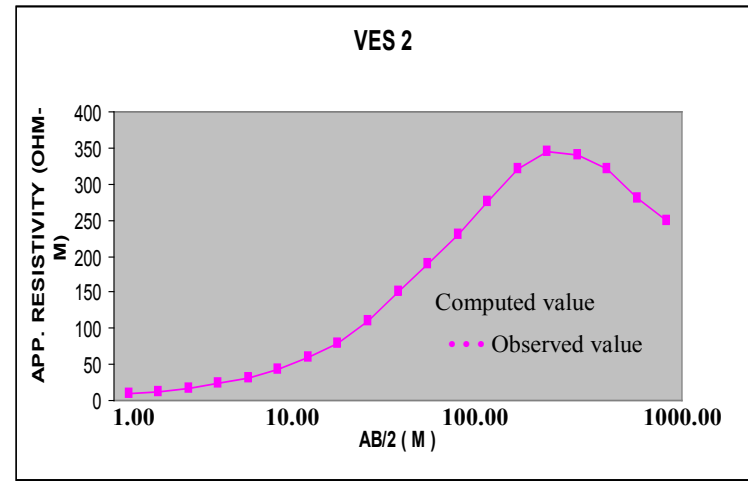

Observed (Field) and Computed (Theoretical) Data Model Parameters

\begin{tabular}{|c|c|c|}
\hline$\frac{A B}{2}(m)$ & $\begin{array}{c}\rho_{a}(\text { ohm }-m) \\
\text { OBSERVED } \\
\text { VALUE }\end{array}$ & $\begin{array}{c}\rho_{a}(\text { ohm }-m) \\
\text { COMPUTED } \\
\text { VALUE }\end{array}$ \\
\hline 1.00 & 9.32 & 9.40 \\
\hline 1.47 & 10.32 & 10.80 \\
\hline 2.15 & 7.61 & 13.31 \\
\hline 3.16 & 18.78 & 16.71 \\
\hline 4.64 & 22.6 & 22.60 \\
\hline 6.81 & 11.59 & 27.40 \\
\hline 10.00 & 141.02 & 32.01 \\
\hline 14.70 & 149.18 & 42.30 \\
\hline 21.50 & 304.80 & 54.60 \\
\hline 31.60 & 846.80 & 68.30 \\
\hline 46.40 & 878.80 & 91.20 \\
\hline 68.10 & 1675.13 & 121.00 \\
\hline 100.00 & 23088.40 & 156 \\
\hline 147.00 & 11540.20 & 200 \\
\hline 215.00 & 1987.56 & 247 \\
\hline 250.00 & 678.87 & 293 \\
\hline 300.00 & 346.67 & 335 \\
\hline 400.00 & 323.45 & 363 \\
\hline 500.00 & 330.34 & 366 \\
\hline 600.00 & 320.89 & 345 \\
\hline 700.00 & 298.56 & 300 \\
\hline 800.00 & 262.43 & 248 \\
\hline & & \\
\hline & & \\
\hline & & \\
\hline & & \\
\hline & & \\
\hline & & \\
\hline & & \\
\hline & & \\
\hline & & \\
\hline
\end{tabular}

Model Parameters

\begin{tabular}{|c|c|c|c|}
\hline $\begin{array}{c}\text { Geoelectric } \\
\text { Layer }\end{array}$ & $\begin{array}{c}\text { Resistivity } \\
(\text { ohm-m) }\end{array}$ & $\begin{array}{c}\text { Thickness } \\
(\mathrm{m})\end{array}$ & $\begin{array}{c}\text { Cumulative } \\
\text { Thickness(m) }\end{array}$ \\
\hline 1 & 372.00 & 3.80 & 3.80 \\
\hline 2 & 380.00 & 25.80 & 29.60 \\
\hline 3 & 441.00 & 91.20 & 120.80 \\
\hline 4 & 572.00 & 119.80 & 240.60 \\
\hline 5 & 269.00 & 122.00 & 362.60 \\
\hline 6 & 515.00 & Infinity & Infinity \\
\hline \multicolumn{4}{|c|}{ RMS Error (\%): 2.04 } \\
\hline
\end{tabular}

\section{Conclusions}

Since the dropping of the resistivities in the VES curves indicates an aquifer layer, therefore, the depth zone that is the sand or sandstone layers corresponds to the existing saturated aquifer in the study area. The study has shown that the application of surface geophysical measurements to the investigation of groundwater for both domestic and industrial use is feasible. The study area is a complex sedimentary area; more research studies to the area are advised. 


\section{REFERENCES}

[1] EMENIKE E.A (2001): Geophysical Exploration for Ground water in a sedimentary environment. Global Journal of pure and applied sciences, Vol 7, No1 January

[2] EKINE A. S and OSOBONYE (1996): Surface Geo-electric sounding for the determination of Aquifer characteristics in parts of Bonny Local Government Area of River State. Nigeria Journal of Physics Vol. 85, pp.93-97

[3] OKWUEZE E.E (1996): Preliminary findings of the groundwater resource potentials from a regional geo-electric survey of the Obudu basement area, Nigeria Global Journal of Pure and Applied sciences Vol. 2, No. 2, pp. 201-211

[4] KOGBE C.A. (1989): Geology of Nigeria. Rock View (Nig.) Ltd., Plot 1234, Zaramaganda, Km.8, Yakubu Gowon Way, Jos, Nigeria. First published 1975
[5] ASOKHIA M.B.(1995): Engineering Geology Services Ltd Lagos, Nigeria

[6] OTTO KOEFOED (1979): Geosounding Principles 1 ESPC-Amsterdam, Oxford, New York

[7] MILSON JOHN (1939): Field Geophysics - a handbook of geophysical society of London. John Wiley \& Sons NY, Toronto, Singapore

[8] REINHARD K. FROHLICH (1974): Combined geo-electric al and Drill-hole investigation for detecting fresh-water aquifers in Northern western Missouri. Geophysics Vol. 39, pg. 340-352

[9] DORBRIN M.D and KING R.F (1976): Introduction to Geophysical prospecting. Mc Graw-Hill book, New York pp.630 